\title{
A DUPLA FACE DE UM CRÍTICO: NOTAS SOBRE " 0 HOMEM DOS AVESSOS", DE ANTONIO CANDIDO
}

http://dx.doi.org/10.11606/issn.2237-1184.v0i30p120-126

Yudith Rosenbaum ${ }^{\mathrm{I}}$

RESUMO

A partir do ensaio "O homem dos avessos", em que Antonio Candido analisa a obra Grande sertão: veredas, de Guimarães Rosa, pretendo mostrar o que chamo de dupla navegação do ensaísta no modo de compor a análise. Trata-se de desentranhar do caminho analítico justamente o movimento duplo e ambíguo que Candido surpreende no autor mineiro, qual seja, a oscilação entre os passos enraizados no realismo, herdeiro da vertente crítica dos anos 30, e o voo inventivo e criativo que singulariza escritor e crítico. Selecionando passagens notáveis do ensaio, busco examinar essa dupla flutuação como procedimento crítico analógico à temática estudada por Candido.

\section{ABSTRACT}

Taking as a point of departure Antonio Candido's essay "O homem dos avessos", in which the Brazilian literary critic Antonio Candido analyzes the novel Grande sertão: veredas, by Guimarães Rosa, I intend to point out what I would call the "double navigation" in the essayist's analytical strategy. My purpose is to identify in Candido's essay the same double and ambiguous movement that the critic highlighted in the novel, namely, the oscillation between the steps rooted in realism, heir to the social critical approach of the 1930s, and the inventive and creative flight that singles out both the writer and the critic himself. By selecting remarkable passages in the essay, I seek to examine this double fluctuation as a critical procedure analogous to the theme studied by Candido.

\section{PALAVRAS-CHAVE:}

Guimarães Rosa; ensaio;

Realismo; fantasia.

\section{KEYWORDS}

Guimarães Rosa; essay;

Realism;

fantasy.

I Universidade de São Paulo, São Paulo, São Paulo, Brasil. 
m primeiro lugar, é preciso esclarecer que não sou especialista na obra de Antonio Candido, ao contrário de muitos estudiosos que participam desse dossiê. Sou uma admiradora e uma leitora de alguns ensaios que se tornaram minha bússola na abordagem de textos específicos, entre eles o que vou comentar hoje, "O homem dos avessos", sobre Grande sertão: veredas. ${ }^{1}$ A fala será breve, mas espero trazer o meu depoimento mais como professora cujo ofício se pautou nesse grande crítico literário e, antes de tudo, um extraordinário professor. Que pena não ter tido o privilégio de ser sua aluna ou de ter convivido com ele, como vários participantes desse evento. Mas tenho uma única e inesquecível experiência com a pessoa de Antonio Candido que gostaria de compartilhar antes de comentar o ensaio citado.

Descontente por nunca tê-lo conhecido e invejosa dos que sempre iam visitá-lo - e nunca me levavam - tive finalmente uma oportunidade quando uma colega da UFBA, Mirella Márcia, esteve em São Paulo a caminho da casa dele. Pulei no táxi sem pedir licença e fomos juntas. Isso se deu meses antes do falecimento do professor. Chegando lá a conversa se estendeu por mais de duas horas, ouvindo as histórias incríveis que a memória prodigiosa de Candido guardava de sua infância e adolescência chegando aos dias atuais. Na despedida, e isso me marcou muito, Candido dá uma boa risada e faz o seguinte comentário: "O melhor para o mundo seria mesmo se acabar!" E isso bem antes das últimas eleições... Só fico pensando o que ele diria hoje após o fatídico 28 de outubro de 2019...

Mas vamos ao nosso assunto. $O$ percurso que vou fazer tem como norte a didática de Antonio Candido ao expor ao seu leitor os passos de um caminho analítico. Por isso, começo lembrando um pequeno grande ensaio que Candido publicou em 1985 e que me despertou para o ensino de literatura como nenhum outro até hoje. $\mathrm{Na}$ sala de aula ${ }^{2}$ é um clássico, ainda vivo e potente para despertar nos alunos, nos docentes e mesmo nos diletantes o prazer do texto, como diria Barthes, e uma estrada segura e aberta para quem deseja penetrar em camadas de significação textual, tendo como guia, sempre generoso com seus seguidores, alguém da estatura de Antonio Candido.

O prefácio já nos dá índices valiosos de seu método de trabalho, que também vamos encontrar no ensaio sobre Grande sertão: veredas. Eu me sirvo desses componentes que compõem $\mathrm{Na}$ sala de aula, ainda que tratem

\footnotetext{
${ }^{1}$ Utilizo a edição do volume Tese e antítese. 3. São Paulo: Companhia Ed. Nacional, 1978. A partir de agora as citações terão apenas o número da página.

2 CANDIDO, Antonio. Na sala de aula. Caderno de análise literária. Rio de Janeiro: Ouro sobre azul, 2017 ( $9^{\mathrm{a}}$ ed.).
} 
de seis poemas, pelos pressupostos que iluminam também o ensaio sobre a prosa de Guimarães Rosa. Nas palavras do Autor, lemos as premissas para o trabalho analítico:

\begin{abstract}
Um desses pressupostos é que os significados são complexos e oscilantes. Outro, que o texto é uma espécie de fórmula, onde o autor combina consciente e inconscientemente elementos de vários tipos. Por isso, na medida em que se estruturam, isto é, são reelaborados numa síntese própria, esses elementos só podem ser considerados externos ou internos por facilidade de expressão. Consequentemente, o analista deve utilizar sem preconceitos os dados de que dispõe e forem úteis, a fim de verificar como (para usar palavras antigas) a matéria se torna forma e o significado nasce dos rumos que esta lhe imprimir. (CANDIDO, 2017, p. 9, grifos do autor)
\end{abstract}

Chamo atenção para algumas palavras, frases e expressões desse prefácio: "significados complexos e oscilantes", "síntese" de elementos conscientes e inconscientes, externos e internos, uso pelo crítico "sem preconceitos" de todos os dados disponíveis e, por fim, a verificação do modo como a matéria se torna forma e é esta que imprime os vários significados. Em tudo isso, segundo o Autor, está implícito o conceito de "estrutura como correlação sistemática das partes" (Idem, p. 9). E ainda "o interesse pelas tensões que a oscilação ou oposição criam nas palavras, entre as palavras e na estrutura, frequentemente com estratificação de significados" (p. 10, grifo do autor).

Ora, é exatamente esse olhar crítico, sem preconceitos, que desvenda tensões, oposições e oscilações nos poemas analisados, que busca no conjunto dos detalhes e das partes uma síntese estrutural, ou seja, uma unidade de significados complexos correlacionados, que rege com extrema acuidade o ensaio "O homem dos avessos".

Publicado inicialmente em 1957, sob o título "O Sertão e o mundo" no n. 8 da Revista Diálogo, dedicado a Guimarães Rosa e conhecendo depois várias edições, o ensaio "O Homem dos avessos", reedita, em sua caminhada analítica, as mesmas linhas de força que o Autor busca acompanhar no romance de Rosa. Haveria, a meu ver, uma dupla navegação desse timoneiro crítico, ao ponto de ser possível estabelecer um paralelo, uma analogia entre o movimento ensaístico propriamente considerado e o que ele dá a ver no texto abordado. É isso que vou tentar mostrar agora.

O Autor começa ressaltando "a absoluta confiança na liberdade de inventar" (p. 121) de Guimarães Rosa. Essa liberdade e essa invenção ganham outros nomes ao longo do texto: "jorro de imaginação criadora" 
(p. 121) na linguagem, na composição, no enredo e na psicologia. Ou ainda, elementos que, na opinião do crítico, Rosa deformou, consciente e inconscientemente, a partir de modelos reais, o que de novo acentua o aspecto inventivo, submetendo os dados de observação naturalista (no caso, o sertão mineiro) ao imperativo da ficção. Candido chega a dizer que a invenção superou por "milagre o poderoso lastro da realidade tenazmente observada, que é sua plataforma" (p. 122). A dialética entre matéria e forma, fato e ficção, mundo e fantasia é o leito fundamental por onde o ensaio flui.

Essa díade entre realidade e imaginação se coloca como a linha mestra do ensaio. A citação da p. 122 revela o alcance do que chamei antes de "dupla navegação" do ensaio e de Guimarães Rosa no romance, ou seja, o crítico precisou observar essa dupla face da obra de Rosa a partir de uma visada também ela dupla, que olha não só os significados manifestos do texto, mas os seus rios subterrâneos que respondem a outras motivações menos visíveis. Cito:

A experiência documentária de G. Rosa, a observação da vida sertaneja, a paixão pela coisa e pelo nome da coisa, a capacidade de entrar na psicologia do rústico - tudo se transformou em significado universal graças à invenção, que subtrai o livro à matriz regional para fazê-lo exprimir os grandes lugares comuns, sem os quais a arte não sobrevive: dor, júbilo, ódio, amor, morte, - para cuja órbita nos arrasta a cada instante, mostrando que o pitoresco é acessório e que na verdade o Sertão é o Mundo. (CANDIDO, 1978, p. 122)

O primado da fantasia conduz o crítico, inclusive, a notar a força do devaneio na recepção da obra, cuja ressonância se daria na "imaginação e na sensibilidade do leitor". Como sabemos por outros textos de Candido, o leitor é concebido como um criador ao lado do escritor, continuando a obra em sua capacidade receptiva.

Prossigo acompanhando em "O homem dos avessos" a íntima tensão entre o polo realista e o arroubo fantasista, cerne do romance e do ensaio. Na comparação entre Grande sertão: veredas e Os sertões, os três elementos estruturais que compõem a analogia principal - a terra, o homem e a luta - são vistos na mesma pendulação das polaridades entre realismo e fantasia. Para o Autor, a atitude euclidiana seria constatar para explicar, enquanto em Rosa seria inventar para sugerir. Ao analisar o modo como a Terra aparece em Grande sertão: veredas, Candido mostra que o meio físico é um suporte ao universo inventado. No mapa, os topônimos que somos capazes de identificar, do norte de Minas ao Piauí, diz Candido, parecem se desarticular e fugir e "certos pontos decisivos só parecem existir como invenções" (p. 124).

A flora e a topografia são percebidas, então, na sua função ficcional, obedecendo a necessidades de composição: “o deserto é sobretudo 
projeção da alma, e as galas vegetais simbolizam traços afetivos". Assim é que Candido desvenda o étimo espiritual (como diria Leo Spitzer ${ }^{3}$ ) que comanda as relações entre acidente físico e realidade geográfica, transformando o rio São Francisco simultaneamente em curso d'água e deus fluvial, eixo do sertão. Simbolicamente os homens transitam entre as margens fasta e nefasta do rio, "tocando as duas metades qualitativas do Sertão, do Mundo, pois Diadorim é uma experiência reversível que une fasto e nefasto, lícito e ilícito, sendo ele próprio duplo na sua condição" (p. 125).

A reversibilidade surge como um modus operandi da obra em seu jogo infinito de versos e reversos, assim como o próprio ensaio de Candido, que ao desdobrar-se em um dos planos do livro - seja o documental, seja o fabular - pende imediatamente ao seu oposto, buscando equilíbrio e ordenação das polaridades. Há um desejo de unidade, sempre notável, ao lado da intuição de sua constante instabilidade opositiva, o que resulta na figura da heterolateralidade, explicada pelo Autor como "a coexistência do real e do fantástico, amalgamados na invenção e, as mais das vezes, dificilmente separáveis" (p. 125). Assim é o Liso do Sussuarão, que passa de um impossível "escampo dos infernos", quando o bando é chefiado por Zé Bebelo, para uma travessia sem dificuldades sob comando de Riobaldo. A natureza simbólica é desentranhada, portanto, das oscilações do enredo.

Enquanto a análise da dimensão da "Terra" revela a sobredeterminação dos homens na relação com o meio, tudo se inverte no quesito "O homem", mostrando agora que eles são produzidos pela realidade envolvente. Os pastos sem fechos, o mundo desregrado, o viver sempre muito perigoso engendram os caminhos errantes dos jagunços, entre a falta da lei e a lei própria. Mas, após verificar os "motivos que formam o valentão sertanejo", ou seja, que o Sertão faz o homem, o crítico é levado a mais uma guinada na apreensão da totalidade, pois, diz ele,

[...] há um homem fantástico a recobrir ou entremear o sertanejo real; há duas humanidades que se comunicam livremente, pois os jagunços são e não são reais. Sobre o fato concreto e verificável da jagunçagem, elaborase um romance de cavalaria, e a unidade profunda do livro se realiza quando a ação lendária se articula com o espaço mágico. (CANDIDO, 1978, p. 129)

\footnotetext{
${ }^{3}$ Como é sabido, em seu ensaio Linguística e história Literária (Madrid: Editorial Grados, 1968), o linguista e mentor da Estilística, Leo Spitzer, trabalha com a concepção de estilo como " desvio", ou seja, um traço (ou uma rede deles) que singulariza o escritor e revela seu étimo espiritual, uma espécie de etimologia comum às particularidades de sua escrita. Spitzer acredita que há uma motivação latente a tais detalhes diferenciados, que levariam à sua raiz psicológica (étimo espiritual), que por sua vez conduziria o crítico do traço de estilo (a alma do escritor) ao traço de época (a sociedade que o gestou). Ver a esse respeito o ensaio "Sob o signo de Hermes", de Adélia Bezerra de Meneses. In: PASSOS, Cleusa Rios P. e ROSENBAUM, Yudith (orgs.). Interpretações. Crítica literária e psicanálise. Cotia /SP: Ateliê editorial, 2014, p. 29-44).
} 
Afinal, o que interessa no livro é o mistério, que varia conforme as circunstâncias. Também a análise do pacto se faz sob a égide da coexistência ou heterolateralidade dos ritos iniciatórios, com direito, de um lado, a fenômenos de possessão demoníaca medieval, braço mágico religioso do livro, e de outro a brutalidade sertaneja em sua rude realidade. Ao final, forja-se o paladino do sertão, categoria híbrida que revela o senso unitário que regia Guimarães Rosa, como fez, acrescento eu, ao nomear, em outro texto, o trabalhador da roça como um "enxadachim". Chamo atenção ao fato de que essa mesma inclinação pela síntese iguala escritor e crítico, ambos movidos pelo perpétuo desdobramento de faces antitéticas na ânsia da unidade.

São muitas as tensões, oposições, oscilações percorridas no ensaio sobre o romance de Rosa, como já anunciara o prefácio de Na sala de aula. Em "O Homem dos avessos", além das figuras da reversibilidade e da heterolateralidade, há que se incluir a ideia de reciprocidade, que avança para a ambiguidade, procedimento que parece abarcar a todos os demais. Cito a passagem em que essas noções se explicitam através do movimento oscilante do narrador e das personagens femininas:

Essas considerações sobre o poder recíproco da terra e dos homens nos levam à ideia de que há em Grande sertão: veredas uma espécie de grande princípio geral de reversibilidade, dando-lhe um caráter fluido e uma misteriosa eficácia [...] A ambiguidade da geografia, que desliza para o espaço lendário; a ambiguidade dos tipos sociais, que participam da Cavalaria e do banditismo; ambiguidade afetiva, que faz o narrador oscilar, não apenas entre o amor sagrado de Otacília e o amor profano da encantadora 'militriz' Nhorinhá, mas entre a face permitida e a face interdita do amor, simbolizada na suprema ambiguidade da mulherhomem que é Diadorim; ambiguidade metafísica, que balança Riobaldo entre Deus e o Diabo, entre a realidade e a dúvida do pacto, dando-lhe o caráter de iniciado no mal para chegar ao bem". (Idem, p. 134)

O que reproduzo a seguir sumariza o que venho acompanhando:

Estes diversos planos da ambiguidade compõem um deslizamento entre os polos, uma fusão de contrários, uma dialética extremamente vida, que nos suspende entre o ser e o não ser para sugerir formas mais ricas de integração do ser. E todos se exprimem na ambiguidade inicial e final do estilo, a grande matriz, que é popular e erudito, arcaico e moderno, claro e obscuro, artificial e espontâneo. (p. 135)

Essa busca pelo "caráter uno, total, do Sertão-enquanto-Mundo" está certamente no cerne da proposta rosiana, em todas as suas narrativas. Mas está também no oficio do crítico, como quis apresentar nesse rápido inventário de trechos do ensaio. Essa mirada de Candido, que surpreende como mote compositivo a duplicidade da mente de Riobaldo entre o mundo da fabulação lendária e o da interpretação racional, termos usados 
pelo crítico, revela-se também ela dividida entre o modo realista de apreensão, onde entram os atributos do sociólogo experiente, e a aposta sempre presente na inventividade literária. Ambas as partes se solidarizam pelo espírito, talvez hegeliano, de construir a totalidade, ainda que dela tenhamos apenas um lampejo.

Afinal, diz o crítico no parágrafo que encerra o ensaio, "na literatura, a fantasia nos devolve sempre enriquecidos à realidade do quotidiano, onde se tecem os fios da nossa treva e da nossa luz, no destino que nos cabe" (p. 139).

Ao ter escrito aqui esse brevíssimo comentário, percebo que o resultado não faz mais do que seguir à risca o andamento de uma escrita, talvez autoevidente. Que reste, então, a beleza das passagens retomadas a título de explanação, cuja potência expressiva se atualiza e se renova a cada nova mirada, para deleite de seus leitores.

\section{Referências bibliográficas}

CANDIDO, Antonio. "O homem dos avessos". In: Tese e Antítese. São Paulo: Companhia Editora Nacional, 1978 (3 ed.), p. 119-29.

CANDIDO, Antonio. Na sala de aula. Caderno de análise literária. Rio de Janeiro: Ouro sobre azul, 2017 (9a ed.).

MENEZES, Adélia Bezerra de. "Sob o signo de Hermes". In: PASSOS, Cleusa Rios P. e ROSENBAUM, Yudith (orgs.). Interpretações. Crítica Literária e Psicanálise. Cotia /SP: Ateliê editorial, 2014, p. 29-44.

SPITZER, Leo. Linguística e história literária. Madrid: Ed. Gredos, 1968 (2a ed.).

Yudith Rosenbaum é professora doutora de Literatura Brasileira da Universidade de São Paulo. É autora, entre outros, dos livros Manuel Bandeira: Uma poesia da ausência (2002, $2^{\mathrm{a}}$ ed.) e Metamorfoses do mal: uma leitura de Clarice Lispector (2006, 2 ${ }^{\mathrm{a}}$ ed.). Contato: yudith@uol.com.br

ORCiD: https://orcid.org/0000-0002-3029-8886 